\title{
Fluid Distribution Analysis of Kite Sail for Application on Ship
}

\author{
Amiadji $^{1}$, Irfan Syarif Arief ${ }^{2}$, Zaki Rizqi Fadhlurrahman ${ }^{3}$
}

\begin{abstract}
- the increasing number of operating ships resulted in high air pollution from the combustion of the ship's engine. Efforts to utilize alternative energy to reduce ship engine work have been done, one of them is using unlimited alternative energy that is wind where one of its application of is the application of new ships sail, kite sail as auxiliary system of ship propulsion. In this final project purposed to find out the value of aerodynamic force of kite sail and power it can generated , with a CFD method that uses 3 kite sail design forms, rectangular, triangular, and elliptical, with an area of $160 \mathrm{~m} 2 \mathrm{this}$ models are simulated at wind speed variations from $13.4 \mathrm{~m} / \mathrm{s}$ up $15.82 \mathrm{~m} / \mathrm{s}$ and angel of attack variation of 15.20 , and 25 . From the variation obtained the total aerodynamic force generated can reach $28.73 \mathrm{kN}$ in rectangular shape, $30.79 \mathrm{kN}$ of Elipsical shape, and $27.55 \mathrm{kN}$ of triangular shape, on variant Angel Of attack 25. From the value of the aerodynamic force, each kite sail capable of generating power, on a rectangular kite sail of up to $263.02 \mathrm{~kW}$, an elipsical $276.75 \mathrm{~kW}$, and a triangular $252.63 \mathrm{~kW}$.
\end{abstract}

Keywords — kite sail, aerodynamic forces, lift force, drag force, wind speed.

\section{INTRODUCTION}

I ncreased number of operating ship all around the world made sea and ocean's pollution getting worse, because the exhaust gas from engine combustion contain such a emissions like NOx, Sox, and CO that known cause green house effect [1-8]. To resolved this problem, people trying to find or use the unconventional energy, and one of them is wind. Using wind as propulsion system is a classic method from long time ago before engine was found, but recently a hybrid propulsion with combination of diesel engine and wind based auxiliary systems are applied on some ships [2]. Considering from social and economic premises at that times, using diesel engine or steam engine instead sail propulsion is a good transition for maritime trading. In early 20th century, there is no concern about sea and ocean's pollution from high fuel consumption, nobody could tought that pollution will become such a serious problem for humanity and environment,. As time passed by, with the development of since and technology, the type and number of ship are boomed as well as the rapid growing global market [9].

More ship operates, more exhaust are produced. Ship exhaust contains harmful air toxics that causes cancer, respiratory illness and premature death. In thi

Amiadji, Department of Marine Engineering, Institut Teknologi Sepuluh Nopember, Surabaya 60111, Indonesia, Email : amiadji @ne.its.ac.id

Irfan Syarif Arief, Department of Marine Engineering, Institut Teknologi Sepuluh Nopember, Surabaya 60111, Indonesia, Email : irfansa@its.ac.id

Zaki Rizqi Fadhlurrahman, Department of Marine Engineering, Institut Teknologi Sepuluh Nopember, Surabaya 60111, Indonesia, Email : zaki13@mhs.ne.its.ac.id circumstances, while oil price has risen leading to important modification for ship systems, to start using unconventional energies that will reduce the pollution and oil use, and wind is one of it that already proved can used for ship propulsion.. There's a lot of wind propulsion system, like rigid sail, wing sail, turbine, flatner rotor, and the recent one is a kite sail. Kite sail is a kite that attached to the ship with steel rope as the towing rope with the purpose to make use of higher wind speed in high altitude and convert it into force that will pull the ship as addition thrust for ship. Kite sail forces appeared by effect of fluid flow that passed it surface, and generate an aerodynamic forces that divided into lift force and drag force. Lift force is a force with direction perpendicular with wind traction and drag force has same direction with wind traction. This forces are generated from pressure difference from upper surface and lower surface of kite sail [10].

Utilizing the kite traction does not mean to fully change the conventional fuel engine propulsion, the concern is making the engine not work at full capacity to get the required ship speed, by using combination propulsion system to covered speed deficit partially using kite's tractive force [1].

\section{A. Force on Kite}

Kite can considered as wing surface that can applied the three principle of forces acting on the kite, there are the weight, tension of towing cable, and aerodynamic force.. the weight is a force that affected by the density and volume of kite and gravity that will act from the center of gravity toward center of the earth. For the aerodynamic force, it has divide into two components, the lift force L, that has been act perpendicular to wind direction and drag force $\mathrm{D}$, that has same direction with incoming wind.

One of the reason using the kite sail was to generate power from wind, where near the ground the wind may swirl, but as higher the altitude, the wind fairly become constant and nearly parallel to surface of the earth, and in thi case, lift force will go to directly opposed to the weight of the kite as shown at figure 1 . 
Fot the cable tension, it will act through the bridle point or the controlling pod where the lne will attached to the kite. The cable tension divided into two pulling

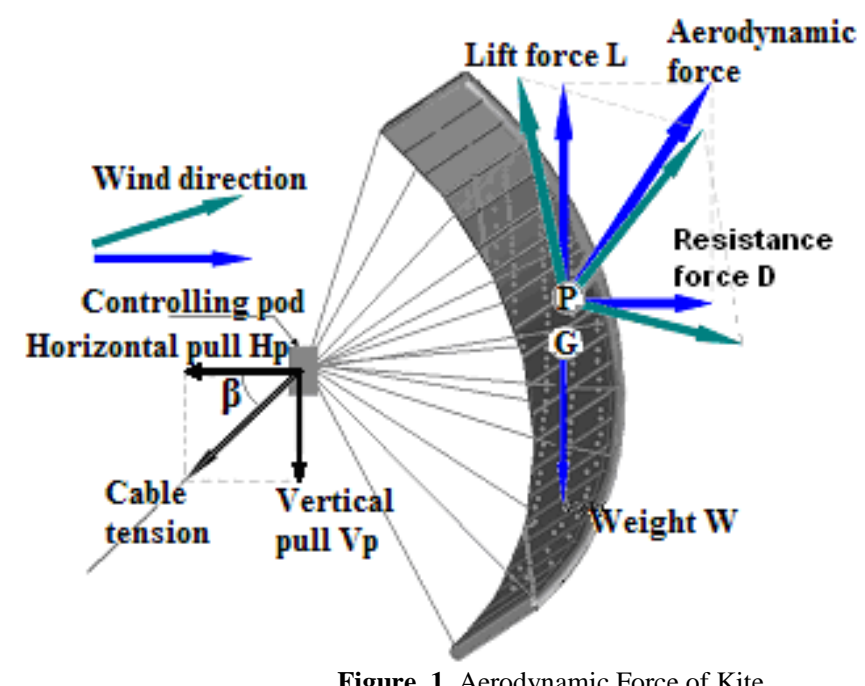

Figure. 1. Aerodynamic Force of Kite

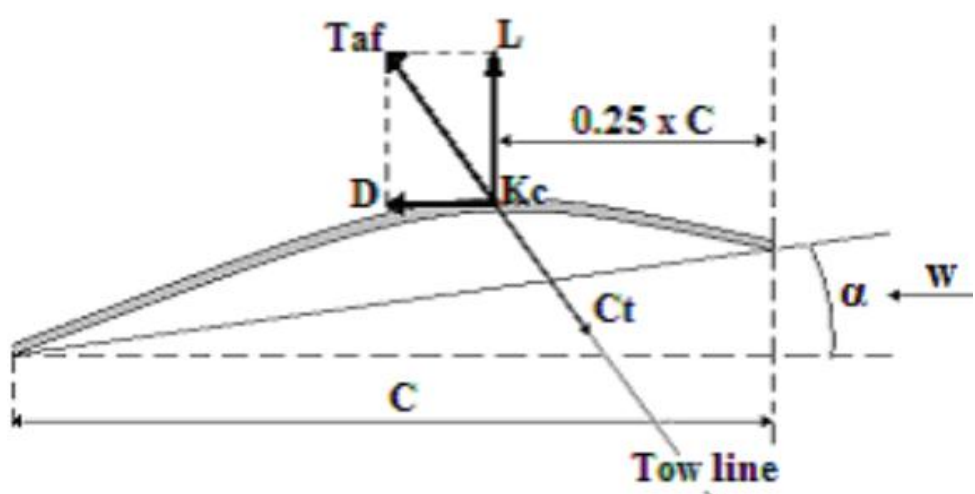

Figure. 2. Formula of Aerodynamic Force

B. Aerodynamic Force on Kite

As explained before, aerodynamic force divided into lift force and drag force . this forces are affected by various factor that will determine the value of the force, there are :

- Area of the kite

- Shape of the kite

- Wind velocity

- Angle of Attack

- Density of the fluid that passed the kite, in this case the air.

The formula to calculate the force based on the the aspect are

$L=\frac{1}{2} \rho C_{L} W^{2} A_{k}$

$D=\frac{1}{2} \rho C_{D} W^{2} A_{k}$
(5)

With the following note based on figure 2 . Where :

$\mathrm{D} \quad=$ resistance force

$\mathrm{L}=$ lift force

Taf $=$ total aerodynamic force

$\mathrm{C}=$ chord

$\mathrm{Ct}=$ towing cable tension (equal value with Taf)

$\alpha \quad=$ incidence angle of wind

$\mathrm{w} \quad=$ wind velocity

$\mathrm{Kc} \quad=$ application center of forces

C. Kite sail's force into power for ship propulsion the main target of using kite sail for propulsion system is to reduce work of engine, by using the kite traction trough the towing rope. When applying a kite for the propulsion of an object on the horizontal plane, e.g. a

$T_{a f}=\sqrt{L^{2}+D^{2}}$ 
ship at sea or a trolley moving along a track, the trajectory of the fixation point itself becomes an important factor [2]. Show in figure 3 where the elevation angle represents the position in the wind window, the fixation point of the tethermoves along the ship's or trolley's course parallel to the true wind while the kite follows its designated flight pattern at its own speed above

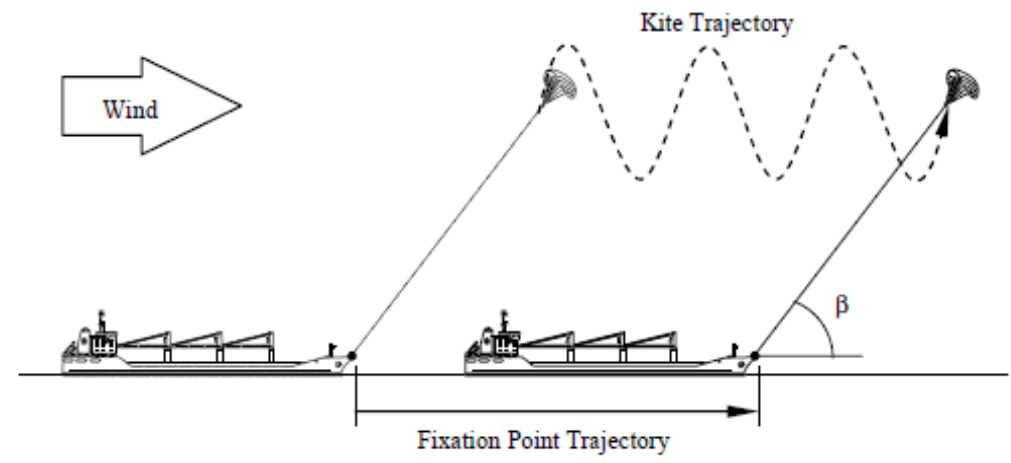

Figure. 3. Trajectory of Aerodynamic Force

To calculate the power generated by kite traction, are determined by fixation or ground pont speed and the equal aligned component of lether force ( cable tension ) with the following formula [6] :

$\mathrm{P}=\mathrm{Vg} \times \mathrm{Ct} \times \cos \beta$

Dimana

$\mathrm{Vg}=$ ground point velocity ( ship velocity) $(\mathrm{m} / \mathrm{s})$

$\mathrm{Ct}=$ cable tension $(\mathrm{kN})$

$\mathrm{B}=$ angle between kite sail and ground $\left({ }^{\circ}\right)$

\section{METHOD}

\section{Data Gathering}

With the purposed to find how much force will generated from kite sail, spesification of the kite are needed for design stage. There are 3 shape of kite are used, rectangular, elipsical and triangular. This designs use same airfoil profile, using NACA 6409 and have flat area $160 \mathrm{~m}^{2}$ with span/chord ration 2.5 .

Using the surfplan software, the result of span $\mathrm{x}$ chord of each form is rectangular $(20 \times 8) \mathrm{m}$, elipsical ( $23.7 \times 8.6) \mathrm{m}$, and triangular $(19.5 \times 11.8) \mathrm{m}$ shown in figure 4 . For wind speed data, because the kite has operating condition between $100-300 \mathrm{~m}$ altitude, the wind speed will more higher than wind speed at sea surface. A surface wind data need to determined wind speed at higher altitude using this calculation :

$$
\begin{aligned}
& \text { Vwz }=\text { Vg x z } \\
& \begin{array}{ll}
\text { Vwz } & =\text { Wind speed at Height } \mathrm{z}(\mathrm{m} / \mathrm{s}) \\
\mathrm{Vg} & =\text { wind speed at surface }(\mathrm{m} / \mathrm{s}) \\
\mathrm{Z} & =\text { altitude }(\mathrm{m})
\end{array}
\end{aligned}
$$

To determine wind direction and wind speed at surface , it is necessary to specify the shipping route to be used, in this case, the domestic shipping route using BATAM SURABAYA route. On the voyage of this route, based on general wind conditions in the area (maret period) with averange wind speed $14 \mathrm{knot}$, then the direction of wind speed mapping as shown in figure 5 , that direction are :

point $1: 21$ from portside (201 derajat)

point $2: 57$ from portside ( 237 derajat )

point 3 : same direction with ship ( 90 derajat )

point $4: 62$ from arahstarboard ( 298 derajat )

with data of wind speed on the surface of the water, the wind speed can be found at the specific height that will be used for kite sail operation. At this time using variations of altitude $100 \mathrm{M}, 150 \mathrm{M}, 200 \mathrm{M}, 250 \mathrm{M}$, and $300 \mathrm{M}$.

To find out the substantial power generated by kite sail, use the following formula (Falko Fritz, 2013):

$\mathrm{P}=\mathrm{Vg} \mathrm{x}$ Taf $\mathrm{x} \cos \beta$

Where

$\mathrm{Vg}=$ speed of ground point (in this case the speed of Ship) (m/ s)

Taf $=$ total aerodynamic force $(\mathrm{kN})$

$\mathrm{B}=$ angle kite sail against $\operatorname{ship}\left({ }^{\circ}\right)$

this kite angle is created from the position of the kite sail against the ship connected to the kite rope, which is influenced from the far kite sail of the ship and the height of the kite sail. The result are shown in tabl;e 2. 


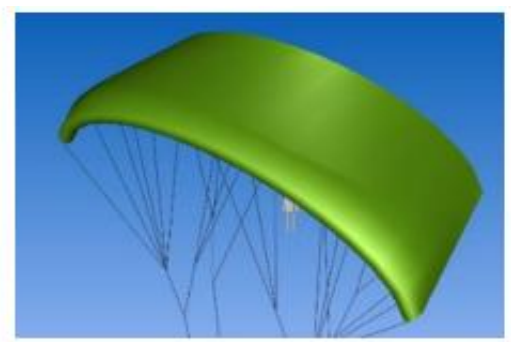

(a)

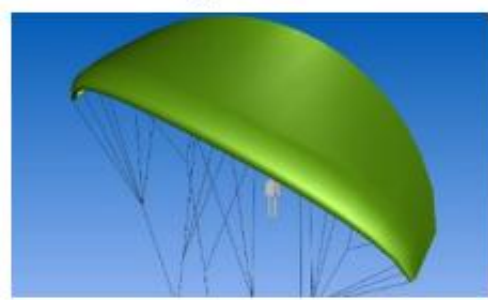

(b)

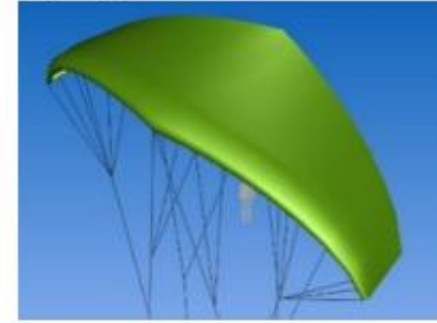

(c)

Figure. 4. Three types of kite form , (a) Rectangular, (b) elipsical, (c) triangular
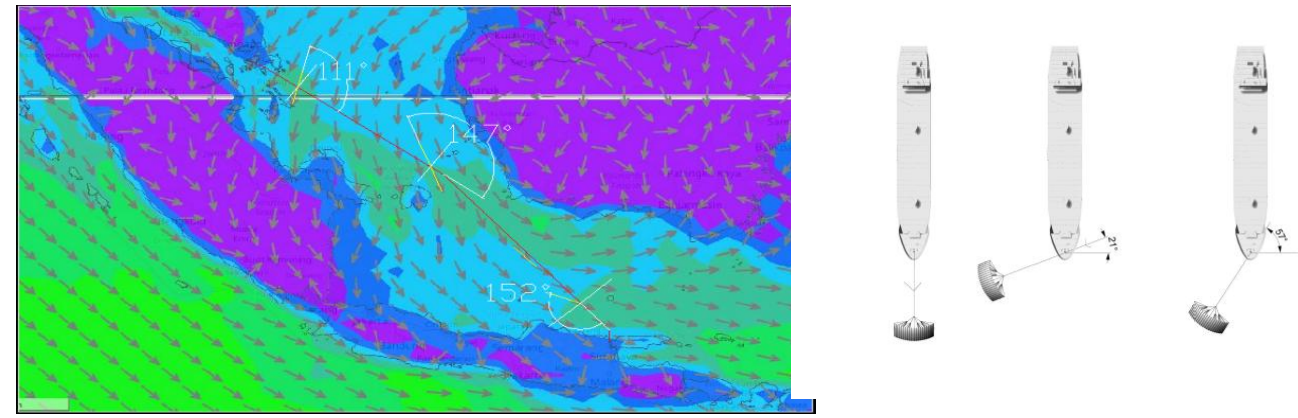

Figure. 5. Ship route Batam -Surabaya with wind direction

TABLE. 1.

WIND SPEED DEPEND ON HEIGHT

\begin{tabular}{ccc}
\hline Height & wind speed $(\mathbf{k n o t})$ & wind speed $(\mathbf{m} / \mathbf{s})$ \\
\hline 100 & 27.04755644 & 13.52377822 \\
\hline 150 & 28.6621712 & 14.3310856 \\
\hline 200 & 29.86588064 & 14.93294032 \\
\hline 250 & 30.8342548 & 15.4171274 \\
\hline 300 & 31.6487364 & 15.8243682 \\
\hline
\end{tabular}

TABLE. 2.

ANGLE BETWEEN SHIP AND KITE SAIL AT SPECIFIC HEIGHT

\begin{tabular}{cc}
\hline Height $(\mathbf{m})$ & $\boldsymbol{\beta}\left(^{(\mathbf{})}\right.$ \\
\hline 100 & 27 \\
\hline 150 & 37 \\
\hline 200 & 45 \\
\hline 250 & 51 \\
\hline 300 & 56 \\
\hline
\end{tabular}

\section{Model Design}

Design process using rhino 3D software, using airfoil profile sourced from airfoiltools website, then made using the size of each form. After the design process is completed, the $3 \mathrm{~d}$ model is positioned with 3 position variations based on the angle of attack

\section{Simulation}

The next step is Modeling kite sail on CFD and doing Simulation to get the value of lift and drag force from each kite sail's Form. Analyze the amount of force acting on the kite sail Can be done by modeling the kite sail and inserting Boundary conditions [5].

The output of this CFD modeling Is the value of Lift and Drag force of kite sail. In Modeling this CFD, the process is divided in three stages, ie Stage pre-processor, flow solver, and post-processor[4].

\section{RESULT AND DISCUSSION}

\section{A. CFD Simulation Result}

The simulation of cfd is done using Ansys Fluent software where from the model which has boundary condition in meshing then done simulation process with variation of velocity determined by wind direction equal to vector determination where y vector is monitored as lift force and vector $\mathrm{x} / \mathrm{z}$ as monitor style Drag depending on where the position of the sail facing, where the results obtained as shown in table 3 
TABLE. 3.

LIFT FORCE AND DRAG FORCE OF KITE SAIL

\begin{tabular}{|c|c|c|c|c|}
\hline Kite sail form & Angle of attack & Wind speed $(\mathrm{m} / \mathrm{s})$ & $\begin{array}{c}\begin{array}{c}\text { Lift } \\
\text { force }(\mathrm{kN})\end{array} \\
\end{array}$ & $\begin{array}{l}\text { drag forct } \\
(\mathrm{kN}) \\
\end{array}$ \\
\hline \multirow{15}{*}{ Rectangular } & \multirow{5}{*}{15} & 13.52377822 & 16.9 & 3.01 \\
\hline & & 14.3310856 & 18.97 & 3.38 \\
\hline & & 14.93294032 & 20.61 & 3.67 \\
\hline & & 15.4171274 & 22.01 & 3.92 \\
\hline & & 15.8243682 & 23.76 & 4.23 \\
\hline & \multirow{5}{*}{20} & 13.52377822 & 16.62 & 4.98 \\
\hline & & 14.3310856 & 18.61 & 5.59 \\
\hline & & 14.93294032 & 20.13 & 6.01 \\
\hline & & 15.4171274 & 21.57 & 6.55 \\
\hline & & 15.8243682 & 23.25 & 7.07 \\
\hline & \multirow{5}{*}{25} & 13.52377822 & 16.93 & 7.9 \\
\hline & & 14.3310856 & 18.99 & 8.86 \\
\hline & & 14.93294032 & 23.01 & 9.55 \\
\hline & & 15.4171274 & 24.56 & 10.2 \\
\hline & & 15.8243682 & 26.54 & 11.02 \\
\hline \multirow{15}{*}{ Elipsical } & \multirow{5}{*}{15} & 13.52377822 & 17.82 & 2.67 \\
\hline & & 14.3310856 & 20.12 & 2.99 \\
\hline & & 14.93294032 & 21.93 & 3.25 \\
\hline & & 15.4171274 & 23.42 & 3.47 \\
\hline & & 15.8243682 & 25.28 & 3.75 \\
\hline & \multirow{5}{*}{20} & 13.52377822 & 19.34 & 5.67 \\
\hline & & 14.3310856 & 21.52 & 6.33 \\
\hline & & 14.93294032 & 23.54 & 6.87 \\
\hline & & 15.4171274 & 25.14 & 7.34 \\
\hline & & 15.8243682 & 27.13 & 7.92 \\
\hline & \multirow{5}{*}{25} & 13.52377822 & 19.68 & 6.76 \\
\hline & & 14.3310856 & 22.43 & 7.69 \\
\hline & & 14.93294032 & 24.66 & 8.89 \\
\hline & & 15.4171274 & 26.07 & 9.87 \\
\hline & & 15.8243682 & 28.78 & 10.97 \\
\hline \multirow{14}{*}{ Triangular } & \multirow{5}{*}{15} & 13.52377822 & 16.07 & 3.02 \\
\hline & & 14.3310856 & 18.04 & 3.388 \\
\hline & & 14.93294032 & 19.59 & 3.679 \\
\hline & & 15.4171274 & 20.92 & 3.93 \\
\hline & & 15.8243682 & 22.58 & 4.28 \\
\hline & \multirow{5}{*}{20} & 13.52377822 & 16.82 & 5.02 \\
\hline & & 14.3310856 & 18.86 & 5.635 \\
\hline & & 14.93294032 & 20.47 & 6.12 \\
\hline & & 15.4171274 & 21.86 & 6.537 \\
\hline & & 15.8243682 & 23.59 & 7.06 \\
\hline & \multirow{4}{*}{25} & 13.52377822 & 18.17 & 7.38 \\
\hline & & 14.3310856 & 20.68 & 8.43 \\
\hline & & 14.93294032 & 22.18 & 8.98 \\
\hline & & 15.4171274 & 23.63 & 9.56 \\
\hline
\end{tabular}

From the table can be seen where the lift force and drag force generated by each form the larger the kite sail when the wind speed faster and also when the angle of the enlarged attack will increase the lift and drag force generated where from the simulation performed the largest results obtained at the speed Wind $15.82 \mathrm{~m} / \mathrm{s}$ at angle of attack 25 .. seeing from the result of the greatest force generated, the ellipsical form is capable of producing the greatest lift style and the rectangular produces the greatest drag force, wherein the result is influenced by the shape of the kite sail, although it has the same area in which (3) 4), the shape of the kite sail will affect the lift and drag coefficient. Where By entering the value of elevator and drag into equation (3) and (4), it will get the value of elevator and drag coefficient. The value of lift and drag coefficients can be seen in table 5 . 
TABLE. 4.

LIFT COEFFICIENT OF KITE SAIL

\begin{tabular}{cccccccccc}
\hline \multirow{2}{*}{$\begin{array}{l}\text { Wind } \\
\text { speed }\end{array}$} & \multicolumn{3}{c}{ Rectangular } & \multicolumn{1}{c}{ Elipsical } & \multicolumn{3}{c}{ Triangular } \\
\cline { 2 - 10 } & $\mathbf{1 5}$ & $\mathbf{2 0}$ & $\mathbf{2 5}$ & $\mathbf{1 5}$ & $\mathbf{2 0}$ & $\mathbf{2 5}$ & $\mathbf{1 5}$ & $\mathbf{2 0}$ & $\mathbf{2 5}$ \\
\hline 13.52 & 0.94 & 0.93 & 0.94 & 0.99 & 1.08 & 1.10 & 0.90 & 0.94 & 1.01 \\
\hline 14.33 & 0.94 & 0.92 & 0.94 & 1.00 & 1.07 & 1.11 & 0.90 & 0.94 & 1.03 \\
\hline 14.93 & 0.94 & 0.92 & 1.05 & 1.00 & 1.08 & 1.13 & 0.90 & 0.94 & 1.01 \\
\hline 15.42 & 0.94 & 0.93 & 1.05 & 1.01 & 1.08 & 1.12 & 0.90 & 0.94 & 1.01 \\
\hline 15.82 & 0.97 & 0.95 & 1.08 & 1.03 & 1.11 & 1.17 & 0.92 & 0.96 & 1.04 \\
\hline
\end{tabular}

TABLE. 5.

DRAG COEFFICIENT OF KITE SAIL

\begin{tabular}{|c|c|c|c|c|c|c|c|c|c|}
\hline \multirow{2}{*}{$\begin{array}{l}\text { Wind } \\
\text { speed }\end{array}$} & \multicolumn{3}{|c|}{ Rectangular } & \multicolumn{3}{|c|}{ Elipsical } & \multicolumn{3}{|c|}{ Triangular } \\
\hline & 15 & 20 & 25 & 15 & 20 & 25 & 15 & 20 & 25 \\
\hline 13.52 & 0.17 & 0.28 & 0.44 & 0.15 & 0.32 & 0.38 & 0.17 & 0.28 & 0.41 \\
\hline 14.33 & 0.17 & 0.28 & 0.44 & 0.15 & 0.31 & 0.38 & 0.17 & 0.28 & 0.42 \\
\hline 14.93 & 0.17 & 0.28 & 0.44 & 0.15 & 0.31 & 0.41 & 0.17 & 0.28 & 0.41 \\
\hline 15.42 & 0.17 & 0.28 & 0.44 & 0.15 & 0.32 & 0.42 & 0.17 & 0.28 & 0.41 \\
\hline 15.82 & 0.17 & 0.29 & 0.45 & 0.15 & 0.32 & 0.45 & 0.17 & 0.29 & 0.42 \\
\hline
\end{tabular}

As can be seen in the table above where the magnitude of both lift and drag coefficients of each different shape, which is influenced by various factors, such as wind velocity that attack the surface of the kite sail, the magnitude of the attack angle of the kite sail, and also the shape of the kite Sail itself, which in general elipsical shape has a small drag force (1)
In searching the total value of aerodynamic force by finding the resultant of the lift and drag using equation (5) with the results that can be seen in the table. With the total aerodynamic force ratio produced can be seen in graph 1.

TABLE. 6.

TOTAL AERODYNAMIC FORCE OF KITE SAIL

\begin{tabular}{cccccccccc}
\hline \multirow{2}{*}{$\begin{array}{l}\text { Wind } \\
\text { speed }\end{array}$} & \multicolumn{3}{c}{ Rectangular } & \multicolumn{3}{c}{ Elipsical } & \multicolumn{3}{c}{ Triangular } \\
\cline { 2 - 10 } & $\mathbf{1 5}$ & $\mathbf{2 0}$ & $\mathbf{2 5}$ & $\mathbf{1 5}$ & $\mathbf{2 0}$ & $\mathbf{2 5}$ & $\mathbf{1 5}$ & $\mathbf{2 0}$ & $\mathbf{2 5}$ \\
\hline 13.52 & 17.17 & 17.35 & 18.68 & 18.02 & 20.15 & 20.81 & 16.35 & 17.55 & 19.61 \\
\hline 14.33 & 19.27 & 19.43 & 20.96 & 20.34 & 22.43 & 23.71 & 18.36 & 19.68 & 22.33 \\
\hline 14.93 & 20.93 & 21.01 & 24.91 & 22.17 & 24.52 & 26.21 & 19.93 & 21.37 & 23.93 \\
\hline 15.42 & 22.36 & 22.54 & 26.59 & 23.68 & 26.19 & 27.88 & 21.29 & 22.82 & 25.49 \\
\hline 15.82 & 24.13 & 24.30 & 28.74 & 25.56 & 28.26 & 30.80 & 22.98 & 24.62 & 27.56 \\
\hline
\end{tabular}

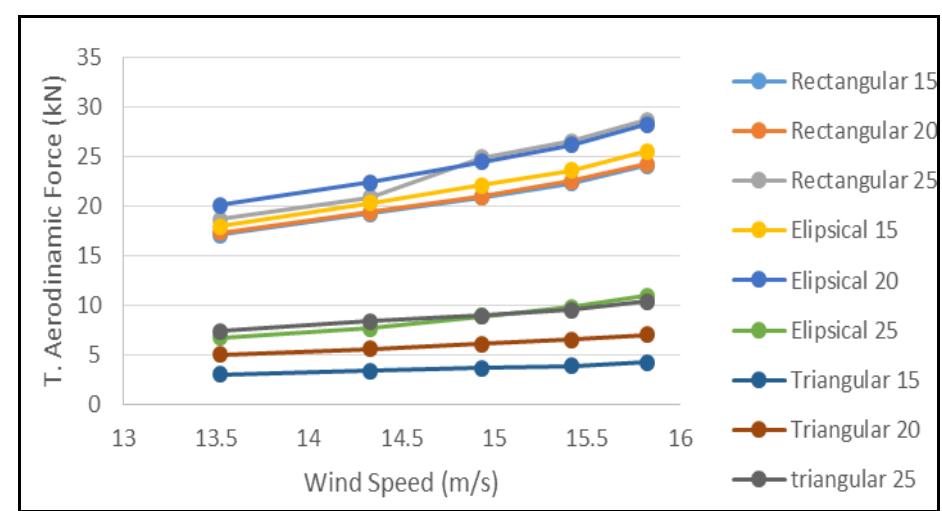

Figure. 6. Total Aerodynamic force of Kite Sails depend on their form 


\section{B. Power Generated by Kite Sail}

The value of the cable tension generated by the kite sail will cause traction on the ship, which can cause the ship to move in the direction of the kite, in other words there will be power to drive the ship. To determine the amount of power generated, using equation (6), where the magnitude of the angle of the beta is the angle between kite sail with the direction of the ship, where it can be seen the force acting on the vessel as in figure 6 . where

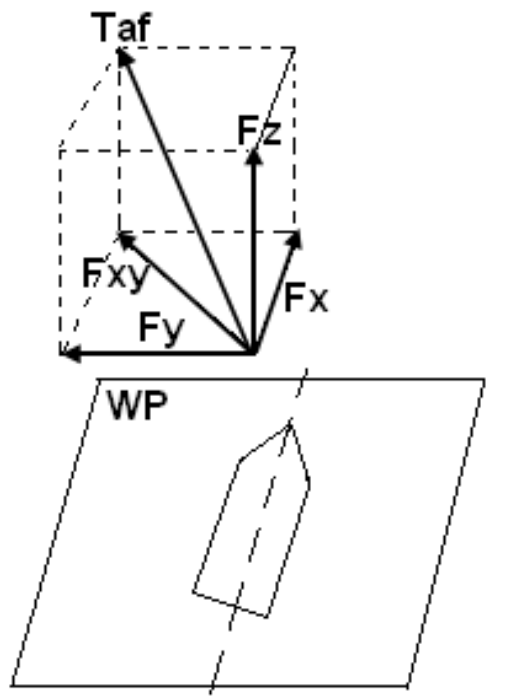

Figure. 7. Direction of forces works on ship at waterplan and angle of kite sail and ship direction

TABLE. 7.

TOTAL AERODYNAMIC FORCE OF KITE SAIL (RECTANGULAR)

\begin{tabular}{|c|c|c|c|c|c|c|}
\hline Kite form & AoA & Vs $(\mathbf{m} / \mathbf{s})$ & Cable Tension $(\mathrm{kN})$ & $\boldsymbol{\beta}$ & $\operatorname{Cos} \beta$ & $\begin{array}{c}\text { Power } \\
(k W)\end{array}$ \\
\hline \multirow{15}{*}{ Rectangular } & \multirow{5}{*}{15} & 13.52 & 17.17 & 27 & 0.891 & 206.84 \\
\hline & & 14.33 & 19.27 & 37 & 0.798 & 220.36 \\
\hline & & 14.93 & 20.93 & 45 & 0.707 & 221.01 \\
\hline & & 15.42 & 22.36 & 51 & 0.629 & 216.80 \\
\hline & & 15.82 & 24.13 & 56 & 0.559 & 213.48 \\
\hline & \multirow{5}{*}{20} & 13.52 & 17.35 & 27 & 0.891 & 209.06 \\
\hline & & 14.33 & 19.43 & 37 & 0.798 & 222.22 \\
\hline & & 14.93 & 21.01 & 45 & 0.707 & 221.79 \\
\hline & & 15.42 & 22.54 & 51 & 0.629 & 218.60 \\
\hline & & 15.82 & 24.30 & 56 & 0.559 & 214.96 \\
\hline & \multirow{5}{*}{25} & 13.52 & 18.68 & 27 & 0.891 & 225.12 \\
\hline & & 14.33 & 20.96 & 37 & 0.798 & 239.65 \\
\hline & & 14.93 & 24.91 & 45 & 0.707 & 263.02 \\
\hline & & 15.42 & 26.59 & 51 & 0.629 & 257.89 \\
\hline & & 15.82 & 28.74 & 56 & 0.559 & 254.20 \\
\hline
\end{tabular}

angle $b$ is the angle between the Taf vectors And Fxy, which indicates that there is a horizontal and vertical force acting on the ship, the vertical force is negligible because it is insufficient to lift the vessel.

In this simulation it is assumed that the kite sail is 200 meters in front of the ship, with a variation of altitude corresponding to that used to find the wind speed, which can be seen in figure 7 . The power generated by kite to propulse the ship are shown in table 7

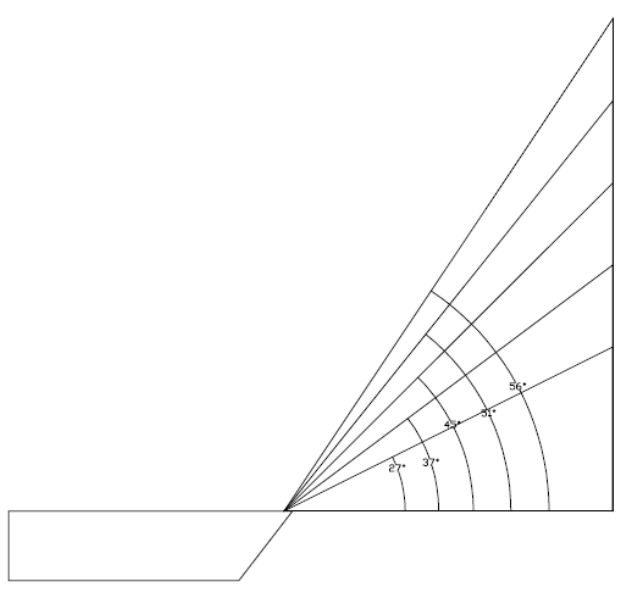$$
\text { . }
$$ 
International Journal of Marine Engineering Innovation and Research, Vol. 1(4), Sept. 2017. 355-363 (pISSN: 2541-5972, eISSN: 2548-1479)

TABLE. 8 .

TOTAL AERODYNAMIC FORCE OF KITE SAIL (ELIPSICAL)

\begin{tabular}{|c|c|c|c|c|c|c|}
\hline Kite form & AoA & $\mathbf{V s}(\mathbf{m} / \mathbf{s})$ & Cable Tension $(\mathrm{kN})$ & $\boldsymbol{\beta}$ & $\operatorname{Cos} \beta$ & $\begin{array}{c}\text { Power } \\
(k W)\end{array}$ \\
\hline \multirow{15}{*}{ Elipsical } & \multirow{5}{*}{15} & 13.52 & 18.02 & 27 & 0.891 & 217.12 \\
\hline & & 14.33 & 20.34 & 37 & 0.798 & 232.62 \\
\hline & & 14.93 & 22.17 & 45 & 0.707 & 234.06 \\
\hline & & 15.42 & 23.68 & 51 & 0.629 & 229.59 \\
\hline & & 15.82 & 25.56 & 56 & 0.559 & 226.07 \\
\hline & \multirow{5}{*}{20} & 13.52 & 20.15 & 27 & 0.891 & 242.85 \\
\hline & & 14.33 & 22.43 & 37 & 0.798 & 256.53 \\
\hline & & 14.93 & 24.52 & 45 & 0.707 & 258.89 \\
\hline & & 15.42 & 26.19 & 51 & 0.629 & 253.97 \\
\hline & & 15.82 & 28.26 & 56 & 0.559 & 250.00 \\
\hline & \multirow{5}{*}{25} & 13.52 & 20.81 & 27 & 0.891 & 250.74 \\
\hline & & 14.33 & 23.71 & 37 & 0.798 & 271.17 \\
\hline & & 14.93 & 26.21 & 45 & 0.707 & 276.75 \\
\hline & & 15.42 & 27.88 & 51 & 0.629 & 270.32 \\
\hline & & 15.82 & 30.80 & 56 & 0.559 & 272.45 \\
\hline
\end{tabular}

TABLE. 9.

TOTAL AERODYNAMIC FORCE OF KITE SAIL (TRIANGULAR)

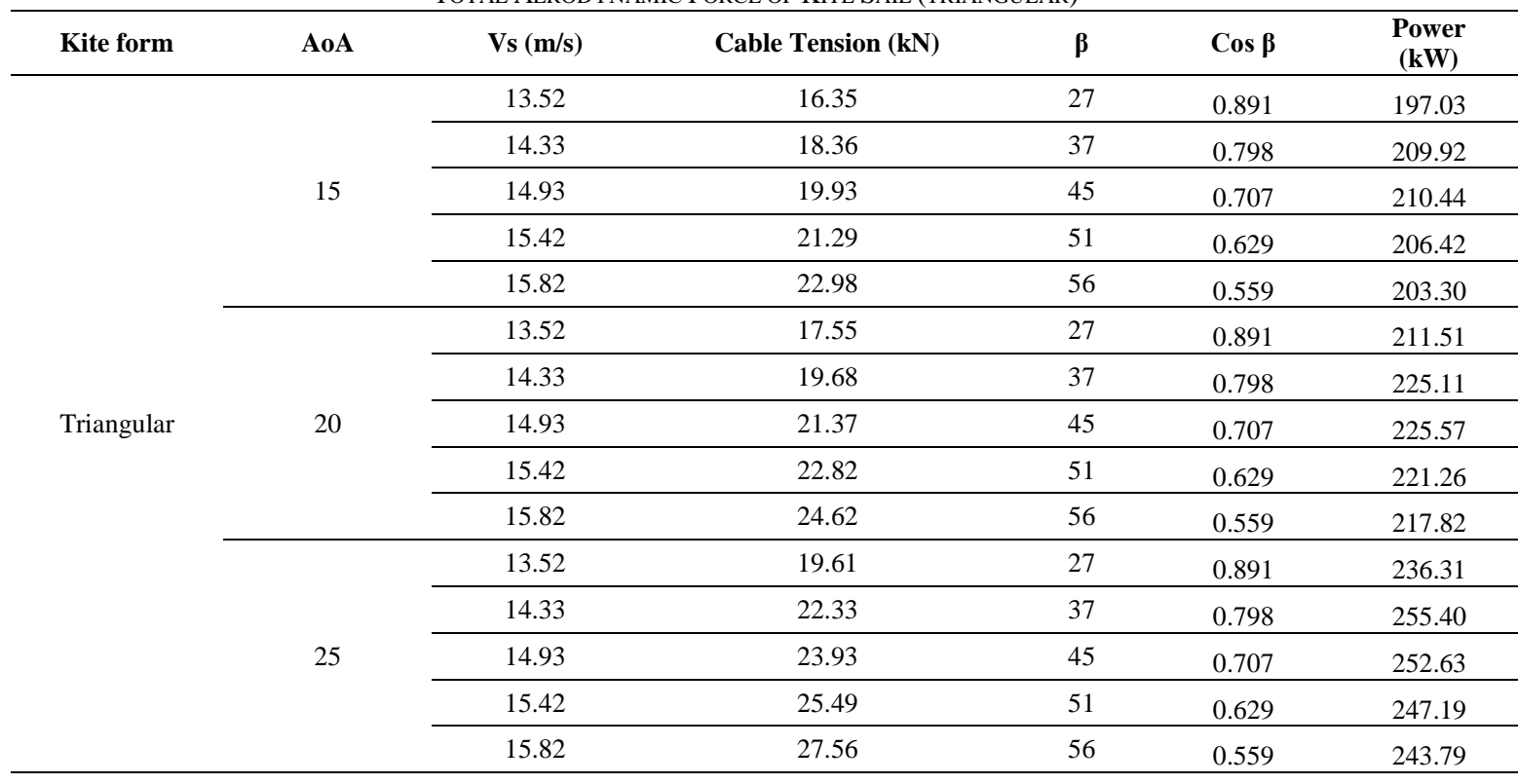

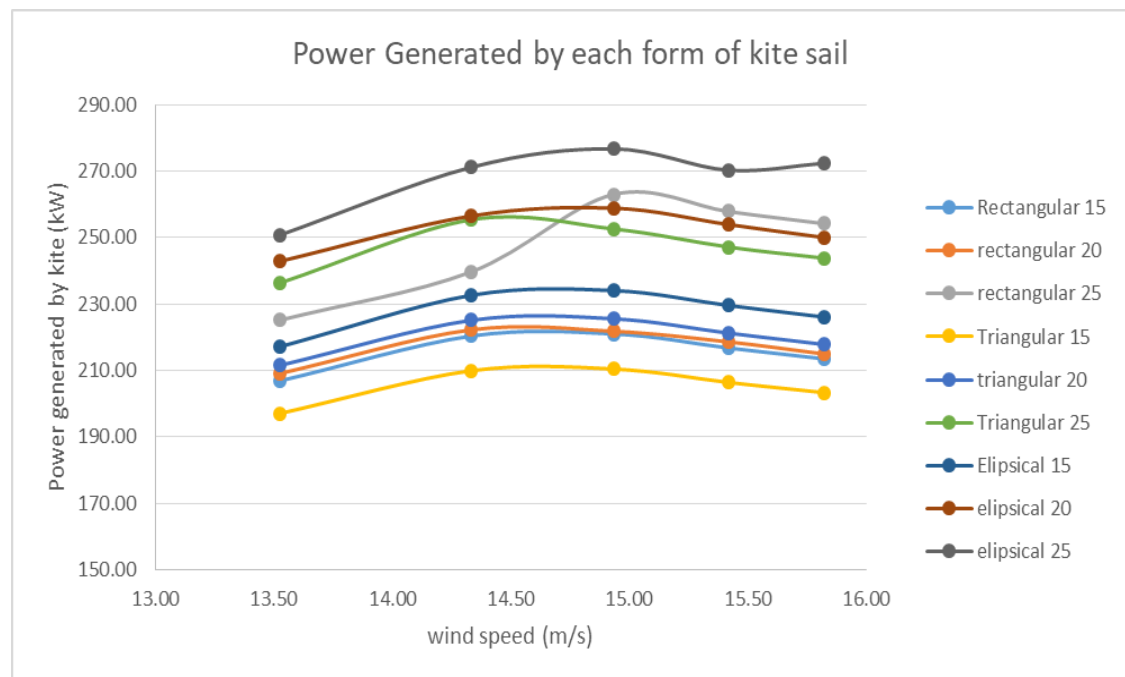

Figure. 8. Power Generated by each form of kite sail 
From the graph and table above, the position of the kite sail will affect the power generated to move the ship. The style that exists between the sleek style of the ship which will bring up the horizontal force acting on the ship whose total force works is a tension cable on a rope crane connecting the kite with the ship. At some point, the power generated will increase. But due to the higher position the resulting horizontal force decreases. From these results can be seen that there are some conditions where kite sail is able to produce optimal power. For the case where the kite sail is attacked from various directions of the wind, on a stationary vessel, there is a distorted movement due to the Fx and Fy forces acting on the ship as shown in figure 6 . for example, if a ship uses a kite sail rectangular with a wind velocity of 15.82 $\mathrm{m} / \mathrm{S}$ with AoA 25, then the amount of deviation generated based on the wind direction used in the simulation can be seen in table 8, where sought Fx and Fy values, with calcuation like below:

$$
\begin{array}{ll}
\text { Fx } & =\text { Fxy } \sin \alpha \\
\text { Fy } & =\text { Fxy } \cos \alpha
\end{array}
$$

even though Fx is smaller but on the ship without any style of rudder it will be deviation

TABLE. 10.

SHIP DIRECTION AFTER KITE SAIL ATTACKED FROM DIFFERENT WIND DIRECTION

\begin{tabular}{ccccccc}
\hline & Direction of wind came from $\left(^{\mathbf{0}}\right)$ & $\boldsymbol{\alpha}\left(^{\mathbf{0}}\right)$ & Fxy (kN) & Fx & Fy & $\begin{array}{c}\text { Ship's } \\
\text { heading }\end{array}$ \\
\hline 90 & Stern & 90 & 16.06827 & 16.06827 & 0 & Ahead \\
\hline 21 & Portside & 69 & 16.06827 & 15.001 & 5.758 & SB \\
\hline 57 & Portside & 33 & 16.06827 & 8.751 & 13.476 & SB \\
\hline 62 & Starbooard & 28 & 16.06827 & 7.543 & 14.187 & PS \\
\hline
\end{tabular}

\section{CONCLUSION}

The use of kite sail as auxiliary system for ship propulsion purposes can be a consideration in selecting solutions to reduce pollution from combustion engine results and can be used to save fuel because by using it is able to lower the engine work to not work at full capacity. Where there are some points to note are:

- the operation of the kite sail is focused on utilizing stable and high wind speeds at certain altitudes.

- the shape and extent of the kite sail will affect the magnitude of the force generated by the kite sail. Where the force will pull the ship through the towing rope that connects the kite sail

- the position of the kite sail will affect the magnitude of the force acting on the vessel, therefore from the whole kite sail system there is a sub-system control to adjust the position of the kite sail against the wind that crashed to produce optimal power.

- looking at the speed and altitude of kite sail work in general, then kite suitable for use on ocean loose like ocean and can not be used continuously where in coastal waters will be very risk if operate kite sail because besides wind not as strong in the middle of sea also disturb Flight path especially for domestic aircraft.

- Kite sail follows the direction of the wind that attacked him, so that if none of the rudder the ship will experience the deviation direction from the previous direction follow the direction of kite sail.

\section{REFERENCES}

[1] Naaijen, Peter. (2013). Performance of Auxilliary Wind Propulsion for Menrchant Ships Using a Kite.

[2] Grosan., Nicolae \& D. Dumitru. (2013). Consideration Regarding Kite Towed Ship's Manouvering

[3] Traut M. , Gilbert P. , Walsh C. , Bows A., Filippone A. , Stansby P., Wood R. 2013. Propulsive power contribution of a kite and a Flettner rotor on selected shipping routes. Elsevier Journal ; 365 366
[4] Putra, Tutut Cahya, Murdijanto, Nasirudin, Ahmad. 2010 Analisis Pengaruh Bentuk Layar terhadap Kontribusi Kecepatan yang dihasilkan oleh KM. Belitung dengan Simulasi CFD (Computational Fluid Dynamics)

[5] .Febrianto, Chepy. 2012. Perancangan Layar Berbentuk Foil untuk Kapal General Cargo 133 M.

[6] Fritz Falco. 2013. Application of an Automated Kite System for Ship Propulsion and Power Generation; 2- 10

[7] Tri Hartanto, Sarjito, Nur Aklis. 2015. Analisa Aerodinamika Flap dan Slat pada Airfoil NACA 2410 terhadap Koefisien Lift dan Koefisien Drag dengan Metode Computational Fluid Dynamic.

[8] I. R. Kusuma, S. Sarwito, and R. A. W. A. Irawati, "Analysis of Electric Propulsion Performance on Submersible with Motor DC, Supply Power 10260AH at Voltage 115VDC," International Journal of Marine Engineering Innovation and Research., vol. 1, no. 2, Mar. 2017.

[9] T. Pitana, S. Gurning, and F. Fikri, "Modelling of LPG Ship Distribution in Western of Indonesia using Discrete Simulation Method," International Journal of Marine Engineering Innovation and Research., vol. 1, no. 3, Jun. 2017.

[10]A. Z. M. Fathallah, W. Busse, and F. R. Clausthaldi, "Fluid Flow Analysis of Jacket Cooling System for Marine Diesel Engine 93 $\mathrm{Kw}$," International Journal of Marine Engineering Innovation and Research., vol. 1, no. 2, Mar. 2017. 